\title{
Inhibition of PC cell-derived growth factor
} (PCDGF)/granulin-epithelin precursor (GEP) decreased cell proliferation and invasion through downregulation of cyclin $D$ and CDK 4 and inactivation of MMP-2

\author{
Yulan Liu ${ }^{\dagger}$, Ling $\mathrm{Xi}^{\dagger}$, Guoning Liao, Wei Wang, Xun Tian, Beibei Wang, \\ Gang Chen, Zhiqiang Han, Mingfu Wu, Shixuan Wang, Jianfeng Zhou, \\ Gang $\mathrm{Xu}$, Yunping $\mathrm{Lu}$ and Ding Ma*
}

Address: Cancer Biology Center, Tongji Hospital, Tongji Medical College, Huazhong University of Science and Technology, Wuhan, Hubei 430030, P. R. China

Email: Yulan Liu - doctorlyl@yahoo.com.cn; Ling Xi - lindaxi02@yahoo.com.cn; Guoning Liao - gnliao@public.wh.hb.cn; Wei Wang - smilenn66@yahoo.com.cn; Xun Tian - tianxunzerg@yahoo.com.cn; Beibei Wang - marryrose79@sohu.com; Gang Chen - gumpc@126.com; Zhiqiang Han - hanzq2003@yahoo.com.cn; Mingfu Wu - wupingfu@163.com;

Shixuan Wang - wang_shixuan@yahoo.com.cn; Jianfeng Zhou - jfzhou@tjh.tjmu.edu.cn; Gang Xu - xugang@tjh.tjmu.edu.cn; Yunping Lu - lunyunping123@yahoo.com; Ding Ma* -dma@tjh.tjmu.edu.cn

* Corresponding author †Equal contributors

Published: 29 January 2007

BMC Cancer 2007, 7:22 doi:10.1186/147/-2407-7-22
Received: 4 November 2005

Accepted: 29 January 2007

This article is available from: http://www.biomedcentral.com/I47/-2407/7/22

(C) 2007 Liu et al; licensee BioMed Central Ltd.

This is an Open Access article distributed under the terms of the Creative Commons Attribution License (http://creativecommons.org/licenses/by/2.0), which permits unrestricted use, distribution, and reproduction in any medium, provided the original work is properly cited.

\begin{abstract}
Background: PC cell-derived growth factor (PCDGF), also called epithelin/granulin precursor (GEP), is an 88$\mathrm{kDa}$ secreted glycoprotein with the ability to stimulate cell proliferation in an autocrine fashion. In addition, some studies indicated that PCDGF participated in invasion, metastasis and survival of cancer cells by regulating cell migration, adhesion and proliferation. Yet the effects of PCDGF on proliferation and invasion of ovarian cancer cells in vitro and the mechanisms by which PCDGF mediates biological behaviors of ovarian cancer have rarely been reported. In the present study we investigated whether and how PCDGF/GEP mediated cell proliferation and invasion in ovarian cancer.
\end{abstract}

Methods: PCDGF/GEP expression level in three human ovarian cancer cell lines of different invasion potential were detected by RT-PCR and western blot. Effects of inhibition of PCDGF expression on cell proliferation and invasion capability were determined by MTT assay and Boyden chamber assay. Expression levels of cyclin DI and CDK4 and MMP-2 activity were evaluated in a pilot study.

Results: PCDGF mRNA and protein were expressed at a high level in SW626 and A2780 and at a low level in SKOV3. PCDGF expression level correlated well with malignant phenotype including proliferation and invasion in ovarian cancer cell lines. In addition, the proliferation rate and invasion index decreased after inhibition of PCDGF expression by antisense PCDGF cDNA transfection in SW626 and A2780. Furthermore expression of CyclinDI and CDK4 were downregulated and MMP-2 was inactivated after PCDGF inhibition in the pilot study.

Conclusion: PCDGF played an important role in stimulating proliferation and promoting invasion in ovarian cancer. Inhibition of PCDGF decreased proliferation and invasion capability through downregulation of cyclin DI and CDK4 and inactivation of MMP-2. PCDGF could serve as a potential therapeutic target in ovarian cancer. 


\section{Background}

PC cell-derived growth factor (PCDGF), also called epithelin/granulin precursor (GEP), is an $88-\mathrm{kDa}$ secreted glycoprotein purified from the conditioned medium of the highly malignant mouse teratoma-derived cell line PC for its ability to stimulate proliferation in an autocrine fashion [1]. In teratoma cells, PCDGF expression was shown to be essential for tumorigenicity [2]. High levels of PCDGF expression are found in rapidly proliferating cells, such as skin cells, deep crypts of gastrointestinal tract, and immune cells. On the other hand, low levels of PCDGF expression are found in cells that are not mitotically active, such as muscle and liver cells $[3,4]$. Overexpression of PCDGF has been linked to the growth and tumorigenicity of human breast carcinomas and to the acquisition of estrogen independence by estrogen receptor-positive breast cancer cells [5-7]. Despite these strong connections with cancer and growth control, PCDGF 's mode of action is not well understood.

In addition, some studies indicated that PCDGF participated in invasion, metastasis and survival of cancer cells by regulating cell migration, adhesion and proliferation [8-10]. In SW-13 adrenal carcinoma cells, the level of PCDGF expression was a major determinant of the intrinsic activity of the mitogen-activated protein kinase, phosphatidylinositol 3'-kinase, and focal adhesion kinase signaling pathways [9]. PCDGF resulted in exogenously stimulated cell growth and sustained cell survival of both ARP-1 and RPMI 8226 cells in a dose- and time-dependent fashion [10].

The role of growth factors in ovarian cancer development and progression is complex and multifactorial. Growth factors identified to date, such as transforming growth factor- $\beta$ (TGF- $\beta$ ), macrophage colony stimulating factor (mCSF), and lysophosphatidic acid (LPA) have been shown to regulate ovarian cancer cell growth and survival in vitro and in vivo [11-14]. Monica BJ et al have reported that PCDGF was overexpressed in invasive epithelial ovarian cancer and was involved in the stimulation of ovarian cancer cell proliferation [15]. Yet the effects of PCDGF on ovarian cancer in vitro and the mechanisms by which PCDGF mediates ovarian cancer biological behaviors have rarely been reported.

As we know, cyclin D1 can stimulate proliferation by driving cells from the G1 into the S-phase of the mammalian cell cycle. Previous studies suggest that the expression of cyclin D1 could be induced by growth factor stimulation, and cdk4 or cdk6 associated with cyclin D1 exhibits protein kinase activity [16-18]. Matrix metallo-proteinases, a family of zinc-dependent metallo-endopeptidases, are known to be involved in tumor invasion and metastasis by degradation of the extracellular matrix. MMP-2, one of these enzymes, is able to degrade type IV collagen, a major component of the basement membrane [19-21].

Understanding the mechanisms by which PCDGF mediates tumor biological behaviors could be valuable for designing potential therapeutic schemes and improving the survival of ovarian cancer patients. In the present study we investigated PCDGF expression level in ovarian cancer cells. We also observed the proliferation rate and invasion index in Sw626 and A2780 cells after transfection with antisense PCDGF cDNA. The expression of cyclin D1, CDK4 and the activity of MMP2 along with the change of PCDGF were determined.

\section{Methods \\ Cell culture}

Human ovarian cancer cell lines SW626, Skov-3 were purchased from the American Type Culture Collection (Manassas). They were maintained in Leibovitz's L-15 and McCoy's 5a media, respectively. Human ovarian cancer cell line A2780 was obtained from China Type Culture Center (Wuhan University) and cultivated in RPMI-1640 medium. All of them were cultured in a $37^{\circ} \mathrm{C}$ incubator supplied with $5 \% \mathrm{CO}_{2}$ and $10 \%$ fetal bovine serum (Invitrogen).

\section{Quantitative RT-PCR analysis of PCDGF mRNA expression}

Total RNA of three human ovarian cancer cell lines was isolated by TRIzolRNA kit (Gibco BRL) according to the manufacturer's protocol, $5 \mu \mathrm{g}$ of total RNA were reverse transcribed into cDNA, then amplified with equal cDNA. In PCR analysis the specific primer pairs used were for PCDGF: forward primer, 5'-AATGTGACATGGAGGTGAGC-3' and reverse primer, 5'-AGCAGGTCTGGTTATCATGG-3'; for GAPDH as internal standard: forward primer, 5'-CCTTCACCATCTTCCAGGAG-3', and reverse primer, 5'-CCTGCTTCACCACCTTCTTG-3'. The reaction mixtures were subjected to 30 cycles of PCR. Each cycle consisted of denaturation at $94^{\circ} \mathrm{C}$ for $30 \mathrm{sec}$, annealing at $58^{\circ} \mathrm{C}$ for $60 \mathrm{sec}$ and extension at $72^{\circ} \mathrm{C}$ for $60 \mathrm{sec} .10 \mu \mathrm{l}$ of each PCR product were analyzed by electrophoresis on $1.5 \%$ agarose gels containing $0.5 \%$ ethidium bromide.

\section{Immunoprecipitation and Western Blot analyses}

Since PCDGF is a secreted protein, its expression was measured in cell lysates and conditioned media collected in the presence of a protease inhibitor mixture of $200 \mu \mathrm{M}$ phenylmethylsulfonyl fluoride (PMSF)/ $1 \mu \mathrm{M}$ leupeptin/ $0.5 \mu \mathrm{M}$ aprotinin/ $1 \mathrm{mM}$ EDTA (all obtained from Sigma). Cells were lysed in PBS containing 1\% Triton X-100 followed by sonication and centrifugation. For comparative studies of PCDGF expression, the samples used for immunoprecipitation and Western blot analysis were normalized to equivalent cell numbers (see figure legends), 
determined by counting cells from duplicate sets of dishes. Immunoprecipitation of PCDGF was carried out by incubating samples for $4 \mathrm{hr}$ with $5 \mu \mathrm{g}$ of affinity-purified anti- PCDGF IgG conjugated to agarose beads followed by centrifugation at $10,000 \times g$ for $10 \mathrm{~min}$. Immune complexes were resuspended in Laemmli sample buffer, boiled for $5 \mathrm{~min}$, and separated by electrophoresis on a $10 \%$ polyacrylamide gel in the presence of SDS. Proteins were electrophoretically transferred to nitrocellulose membrane (Schleicher \&Schuell) and conjugated to horseradish peroxidase in the presence of $1 \%$ BSA. Immunoreactivity was visualized by the enhanced chemiluminescence detection system (Amersham). The membranes were then blocked with $5 \%$ nonfat milk overnight at $4{ }^{\circ} \mathrm{C}$ and then incubated for $1 \mathrm{hr}$ at room temperature with 10 $\mathrm{ng} / \mathrm{ml}$ of polyclonal rabbit anti-PCDGF antibody (1:500, Santa Cruz, CA), followed by incubation with HRP-conjugated goat anti-rabbit-IgG. Immunoreactive proteins were detected by an enhanced chemiluminescence kit (Pierce, Rockford, IL).

Quantitative analysis of the RT-PCR and Western blotting was performed with an imaging densitometer.

\section{Proliferation assay}

Ovarian cancer cells in logarithmic growing phase were detached with $0.25 \%$ trypsin. Then $5 \times 10^{5}$ cells were seeded in each well of 24-well plates. After incubation for $72 \mathrm{~h}$, cell monolayers were fixed and stained with $0.5 \%$ crystal violet in $20 \%$ methanol. Specially bound dye was eluted with a 1:1 solution of $0.1 \mathrm{M}$ sodium citrate (PH 4.2): $100 \%$ ethanol. Absorbance at $540 \mathrm{~nm}$ was determined using a microplate reader (BTX).

\section{Matrigel invasion assay}

Cell invasion was assessed by a Matrigel invasion assay, using Transwell chambers (Costar) with 5 - $\mu \mathrm{m}$ pore polycarbonate filters. The filters were coated with $50 \mu \mathrm{g}$ of growth factor-reduced Matrigel (VWR Canlab, Montreal, Quebec, Canada). Cells $\left(5 \times 10^{3}\right)$ in $25 \mu$ of serum-free DMEM were placed on each filter, and $26.5 \mu \mathrm{l}$ of NIH3T3 conditioned medium were placed in the lower chamber as chemo-attractant. $10 \mathrm{~h}$ later the filters were washed, fixed, and stained as described. Cells on the upper surface of the filters were removed with cotton swabs. Cells that had invaded to the lower surface of the filter were counted by microscopy selecting 10 random fields per filter $(\times 400$ magnification).

\section{Construction and transfection of antisense PCDGF CDNA expression vector}

An antisense PCDGF cDNA expression vector was constructed by inserting a partial human PCDGF cDNA (-30 bp to $465 \mathrm{bp})$ into a pcDNA3.1(+) mammalian expression vector (Invitrogen) in the antisense orientation. The recombinant plasmid was certified by DNA sequencing. 4 $\mu \mathrm{g}$ of the antisense PCDGF cDNA construct were transfected into SW626 and A2780 cells with Lipofectamine (GIBCO) respectively. Each transfectant was selected and maintained in $800 \mu \mathrm{g} / \mathrm{ml} \mathrm{G} 418$, stable clones were isolated after 3 wks and identified by quantitative RT-PCR and Western blot analysis. SW626 and A2780 cells were transfected with pcDNA3.1 (+) empty vector plasmid DNA (vector group). Cells receiving only added Lipofectamine (Lipofectamine group), or only added medium (blank group) were used as controls.

In order to rule out the possibility of the non-specific effect, we also transfected PCDGF siRNA (h) (Santa Cruz, CA) into SW626 and A2780 cells according the manufacture instructions. $48 \mathrm{~h}$ after transfection RT-PCR and western blot were used to evaluate the knock down effects.

\section{MTT assay}

Transfected SW626 and A2780 cells were detached with $0.25 \%$ trypsin during logarithmic growing phase. After the cell density was adjusted to $10^{5} / \mathrm{ml}, 100 \mu \mathrm{l}$ of cell suspension was seeded in 96-well plates, and cultured in corresponding medium containing $10 \%$ serum for $48 \mathrm{~h}$. Then $15 \mu \mathrm{l}$ of thiazolyl blue $(10 \mathrm{~g} / \mathrm{L})$ was added in each well and incubated at $37^{\circ} \mathrm{C}$ for $3 \mathrm{~h}$ until formazan was formed. Then $100 \mu \mathrm{l}$ DMSO was added into each well as a solvent. Absorbance was examined at $570 \mathrm{~nm}$ using a microplate reader (BTX).

Western Blot detection of cyclin DI and CDK4 expression Total cell lysates were prepared from subconfluent cells using lysate buffer [50 mM Tris $\mathrm{HCl}$ (pH8.0), $150 \mathrm{mM}$ $\mathrm{NaCl}, 0.1 \%$ SDS, $100 \mu \mathrm{g} / \mathrm{ml}$ PMSF, $10 \mu \mathrm{g} / \mathrm{ml}$ Aroptinin, $\left.1 \% \mathrm{NP}-40,0.5 \% \mathrm{Na}_{3} \mathrm{VO}_{4}\right]$. Sixty micrograms of cell lysate were separated by SDS/PAGE on a $10 \%$ polyacrylamide gel and transferred to nitrocellulose membrane (Schleicher \&Schuell). The membranes were then blocked with $5 \%$ nonfat milk overnight at $4{ }^{\circ} \mathrm{C}$ and then incubated for $1 \mathrm{hr}$ at room temperature with monoclonal mouse anti-cyclin D1 antibody (1:500, Santa Cruz, CA) and polyclonal rabbit anti-CDK4 antibody (1:500, Santa Cruz, CA) respectively, followed by incubation with HRP-conjugated goat anti-mouse-IgG or goat anti-rabbit-IgG. Immunoreactive proteins were detected by an enhanced chemiluminescence kit (Pierce, Rockford, IL).

\section{Quantitative RT-PCR and zymography analysis of MMP-2 mRNA expression and activity}

Total RNA from four groups of human ovarian cancer cells was isolated by TRIzolRNA kit (Gibco, BRL, Gaithersburg, $\mathrm{MD}$ ) according to the manufacturer's protocol, $5 \mu \mathrm{g}$ of total RNA were reverse transcribed into cDNA, then amplified with equal CDNA. In PCR analysis the specific primer pairs used for MMP-2 were: forward primer, $5^{\prime}-$ - 
GTGCTGAAGGACACACTAAAGAAGA--3' and reverse primer, 5'-TTGCCATCCTTCTCAAAGTTGTAGG-3'; Thirty cycles were completed at $94^{\circ} \mathrm{C}$ for $30 \mathrm{~s}, 58^{\circ} \mathrm{C}$ for 60 s and $72^{\circ} \mathrm{C}$ for 60 s during each cycle.

Gelatin zymography was performed to measure the activity of MMP-2 in SW626 cells. Conditioned medium from equal numbers of cells grown under serum-free conditions for $24 \mathrm{hr}$ were electrophoresed on $10 \%$ denaturing SDS/PAGE containing $1 \mathrm{mg} / \mathrm{ml}$ gelatin at $4{ }^{\circ} \mathrm{C}$, then washed $1 \mathrm{~h}$ in $2.5 \%$ TritonX-100 and incubated $16 \mathrm{~h}$ at $37^{\circ} \mathrm{C}$ in reaction buffer $[50 \mathrm{mmol} / \mathrm{L}$ Tris, $10 \mathrm{mmol} / \mathrm{L}$ $\mathrm{CaCl} 2,200 \mathrm{mmol} / \mathrm{L} \mathrm{NaCl}, 1 \mu \mathrm{mol} / \mathrm{L} \mathrm{ZnCl} 2$ (pH = 7.5)]. Gels were stained with coomassie blue and destained. Gelatin activities were evaluated by luminance and area of bands against blue background.

\section{Statistical analysis}

All experiments were repeated independently three times, and data were expressed as mean \pm SD. Correlation and One-Way ANOVA were used for statistical analysis. $P<$ 0.05 was considered as the level of significance.

\section{Results}

\section{PCDGF mRNA and protein expression}

To detect mRNA and protein expression level of PCDGF in three ovarian cancer cell lines, quantitative RT-PCR and Western blot assay were used. The absorbency ratio of objective bands to reference bands was taken as the quantification standard. In RT-PCR experiments, comparative absorbencies of SW626, A2780 and Skov-3 cells were 3.69 $\pm 0.05,2.83 \pm 0.05$ and $0.86 \pm 0.02$ respectively (Fig. 1A). One-Way ANOVA analysis exhibited that there are significant differences among groups $(P<0.05)$; In Western blot assay the ratios in the three cell lines were $0.33 \pm 0.05$, $0.27 \pm 0.04,0.15 \pm 0.04$ (Fig. 1B). The difference between SW626 and A2780 was not significant $(P>0.05)$, while the differences between either of them and Skov-3 were significant $(P<0.05)$. These results indicate that levels of PCDGF transcription and translation were coincident in three ovarian cancer cell lines

\section{Cell proliferation and invasion capabilitiy}

To investigate the correlation between the expression levels and the malignant phenotype, cell growth assays and Boyden chamber in vitro invasion assays were used to evaluate the capability of proliferation and invasion in these cells. Cell proliferation capability was figured as absorbency at $570 \mathrm{~nm}$. The OD570 in SW626, A2780 and Skov- 3 cells were $4.05 \pm 0.09,3.85 \pm 0.12$ and $1.01 \pm 0.06$ respectively (Fig. 1C). There were no significant differences between SW626 and A2780 $(P>0.05)$, but there were significant differences between them and Skov-3 ( $P$ $<0.05)$.
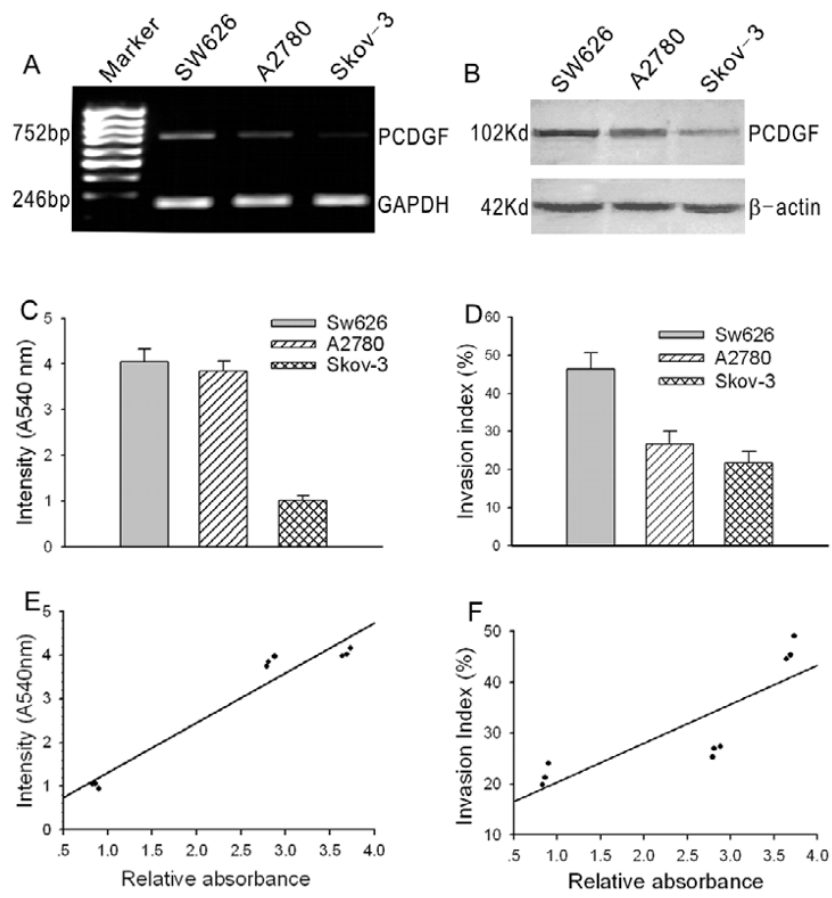

Figure I

PCDGF expression in three ovarian cancer cell lines and its correlation with their malignant phenotype. A, PCDGF mRNA expression levels in SW626, A2780 and SKOV3 cell lines were determined by RT-PCR. The figure shows a representative result of three independent experiments. B, PCDGF protein expression levels in SW626, A2780 and SKOV3 cell lines were determined by western blot. Also the figure shows a representative result of three independent experiments. C, cell proliferation capability of SW626, A2780 and SKOV3 cells determined by MTT assay. Intensity on $540 \mathrm{~nm}$ reflects the cell proliferation capability. Values represent the mean \pm SE from three independent experiments. D, cell invasion capability of SW626, A2780 and SKOV3 cells detected by transwell chambers. The ratio of the number of cells migrating through matrigel to the number of cells migrating without matrigel was defined as invasion index. Values represent the mean \pm SE from three independent experiments. E, the correlation analysis of PCDGF mRNA expression level and cell proliferation capability using Bivariate Correlations in SPSS I2.0. F, the correlation analysis of PCDGF mRNA expression level and cell invasion capability using Bivariate Correlations in SPSSI2.0.

The ratio of the number of cells migrating through matrigel to the number of cells migrating without matrigel was defined as the invasion index. The invasion index was highest in SW626 (46.34 $\pm 2.40 \%)$, lower in A2780 (26.56 $\pm 1.09 \%)$ and lowest in Skov-3 cells $(21.77$ $\pm 2.18 \%$ ) (Fig. 1D). One-Way ANOVA analysis demonstrated that there were significant differences between SW626 and A2780 or Skov-3 $(P<0.05)$, but there was no 
significant difference between A2780 and Skov-3 cells ( $P$ $>0.05)$.

The data indicated that there was a strong correlation between the levels of PCDGF mRNA expression and the capability of proliferation and invasion in ovarian cancer cell $\left(r_{1}=0.97, r_{2}=0.89\right)$ (Fig. 1E), GEP protein also reflected this correlation $\left(r_{1}=0.85, r_{2}=0.84\right)$ (Fig 1F). Our results suggested that PCDGF may play multiple independent roles in the processes of ovarian cancer occurrence and development.

Transfection of antisense PCDGF cDNA expression vector To provide a good experimental model for further study of the molecular characteristics of PCDGF, after sequencing, the antisense PCDGF eukaryotic expression vector was transfected into highly malignant ovarian cancer cell lines by lipofectamine. The stable transfectants were selected with G418. The expression levels of PCDGF mRNA and protein decreased sharply in antisense PCDGF transfected cells detected by RT-PCR and western blot. There were significant differences between cells transfected with antisense PCDGF construct and empty vector $(P<0.05)$, The inhibitory rates were $53 \%$ of mRNA and $72 \%$ of protein expression in Sw626 cells (Fig. 2), and 50\% and 70\% in A2780 cells (data not shown), respectively. However there are no significant differences between the expression levels of control groups $(P>0.05)$.

Similar results were observed in the PCDGF SiRNA transfected ovarian cells. PCDGF protein expression level was inhibited by $82 \%$ in SW626 cells and 76\% in A2780 cells $48 \mathrm{~h}$ after PCDGF SiRNA transfection (data to be published).

\section{Effects of antisense PCDGF on proliferation and invasion}

To observe the inhibitory effects of antisense PCDGF on proliferation and invasion of highly malignant ovarian cancer cells, MTT assay and Boyden chamber in vitro invasion assay were used to detect the changes of proliferation and invasion capability in those cells before and after transfection. The absorbency on $570 \mathrm{~nm}$ and the invasion index decreased almost 2.5 fold in SW626 and A2780 cells transfected with antisense PCDGF construct than with empty vector, with significant differences $(P<0.01)$ (Fig. 3). There were no significant differences between the 3 control groups $(P>0.05)$. These data suggested that antisense PCDGF could remarkably inhibit the proliferation and invasion of highly malignant ovarian cancer cells.

Also similar results were observed in the PCDGF SiRNA transfected ovarian cells. The proliferation rates and invasion index decreased in the SW626 cells and A2780 cells after PCDGF SiRNA transfection (data to be published).
These data demonstrated that knockdown of PCDGF by transient transfection of SiRNA could also lead to reversal of malignant phenotype of ovarian cancer cells.

\section{Expression of MMP-2, Cyclin DI and CDK4}

The effects of PCDGF on the expression and activity of MMP-2 were evaluated by a quantitative RT-PCR method and zymography assay respectively. Our results indicated that MMP-2 gene transcription level did not change in SW626 after transfection of the antisense PCDGF, while MMP-9 decreased, which suggested that activation of MMP-2 was inhibited significantly after PCDGF inhibition (Fig. 4A, 4B). To make a pilot study whether other factors were involved in, the protein expression levels of CyclinD1 and CDK4 before and after transfection were detected by Western blot method. These observations provide evidence that the protein expression of CyclinD1 and CDK4 in antisense PCDGF transfected cells was much lower than other transfection groups (Fig. 4C).

\section{Discussion}

Ovarian cancer is the leading cause of death from gynecologic malignancies because of its special characteristics of histology and anatomy [22]. Defining more sensitive biomarkers of ovarian cancer may aid in the development of targeted therapeutics. PCDGF was originally identified through studies of the role of autocrine growth factors on the acquisition of tumorigenic properties in teratoma tumors and purified as a secreted growth factor from the highly tumorigenic teratoma PC cells. Biochemical characterization showed that it was an 88 -kDa glycoprotein with a $20-\mathrm{kDa}$ carbohydrate moiety, whereas amino acid sequencing showed that PCDGF corresponded to a family of $6-\mathrm{kDa}$ double cysteine-rich polypeptides. The $6-\mathrm{kDa}$ epithelins, originally purified from rat kidney extracts, were shown to be dual growth modulators for a variety of epithelial cell lines. Recently it was reported that PCDGF might play an important role in tumorigenicity, invasion and survival in various tumors such as human breast cancer, adrenal carcinoma, prostatic adenocarcinoma and multiple myeloma [1-5]. Neutralizing anti- PCDGF antibody reversed basal as well as LPA, ET-1 and 8-CPTinduced ovarian cancer cell growth and induced apoptosis, indicating that PCDGF is a growth and survival factor for ovarian cancer, induced by LPA and ET-1 and CAMP/ EPAC through ERK1/2 [23]. However, studies on expression of PCDGF in ovarian cancer cells and the potential molecular basis of its effects on proliferation and invasion have rarely been reported. Few studies indicated a potential mechanism by cyclin and matrix metalloproteinase.

In our study we detected mRNA and protein expression of PCDGF in three ovarian cancer cells by quantitative RTPCR and Western blot assays. The results indicated that PCDGF was strongly expressed in SW626 and A2780 cells, 

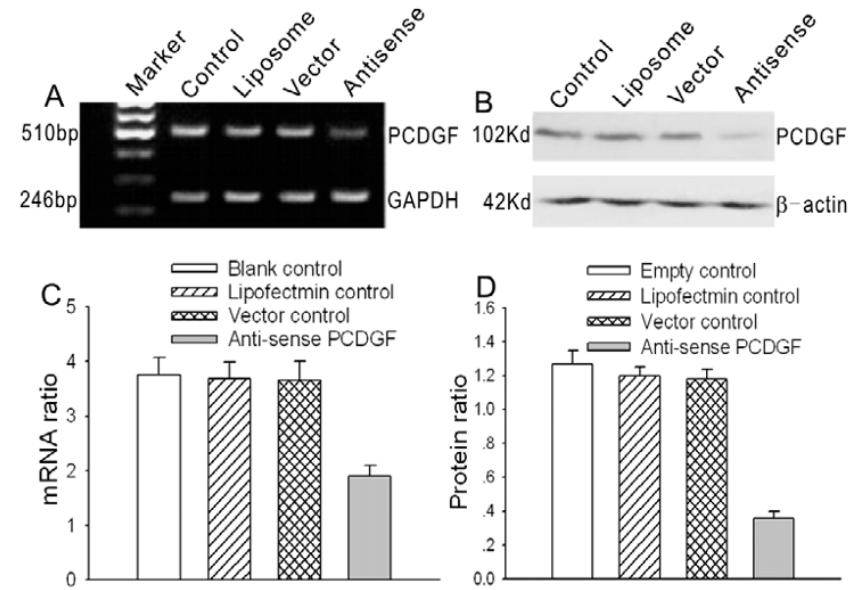

Figure 2

PCDGF expression level after PCDGF antisense vector and control vectors transfection in SW626 cells. A, PCDGF mRNA expression levels were detected by RTPCR after transfection of antisense PCDGF construct and three control groups including empty control, liposome control and control vector. The figure shows a representative result of three independent experiments. B, PCDGF protein expression levels were detected by western blot after transfection of antisense PCDGF construct and three control groups as above. C, quantitative detection of PCDGF mRNA level after PCDGF antisense vector and control vectors transfection in SW626 cells compared with GAPDH. Values represent the mean \pm SE from three independent experiments. D, quantitative detection of PCDGF protein level after PCDGF antisense vector and control vectors transfection in SW626 cells compared with $\beta$-actin. Values represent the mean \pm SE from three independent experiments.

whereas it was weakly expressed in SKOV3 cells. The expression levels of PCDGF in three ovarian cancer cells were coincident with their malignant phenotype. Cell growth assay and Boyden chamber in vitro invasion assay were employed to evaluate the capability of proliferation and invasion. The capability of proliferation and invasion showed the same trend: SW626 > A2780 > Skov-3. Bivariate correlation analysis indicated that PCDGF mRNA and protein expression were positively correlated with the capability of proliferation and invasion in ovarian cancer. So we hypothesised that PCDGF may play multiple roles in the process of ovarian cancer occurrence and development as an independent factor, and may be a new molecular target for ovarian cancer.

To provide a good experimental model for further study of molecular characteristics of PCDGF, the eukaryotic expression vector for PCDGF antisense RNA was constructed successfully, transfected into highly malignant
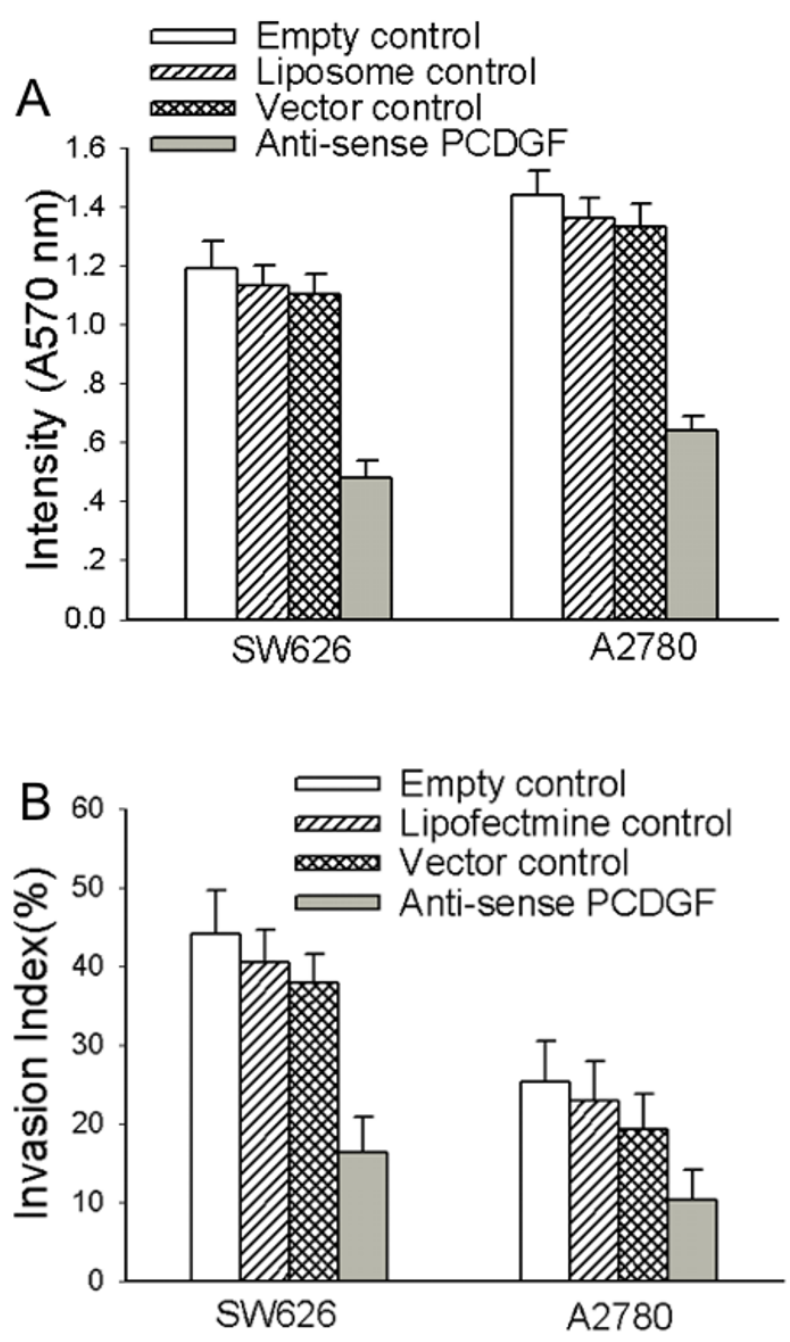

Figure 3

Cell proliferation and invasion capability decreased after antisense PCDGF construct transfection in SW626 and A2780 cells. A, cell proliferation capability was determined by MTT assay after transfection of antisense PCDGF construct and three control group. Intensity on $\mathbf{5 4 0}$ $\mathrm{nm}$ reflects the cell proliferation capability. Values represent the mean \pm SE from three independent experiments. $B$, cell invasion capability was detected by transwell chambers. The ratio of the number of cells migrating through matrigel to the number of cells migrating without matrigel was defined as invasion index. Values represent the mean \pm SE from three independent experiments. Intensity on $570 \mathrm{~nm}$ of cells and invasion index were looked as criterions judging the capability of proliferation and invasion.

ovarian cancer cell lines by lipofectamine, and then detected by RT-PCR and Western-blot assay. The expression levels of PCDGF mRNA and protein decreased sharply in antisense PCDGF transfected cells as expected, which suggested that antisense PCDGF might be an effec- 


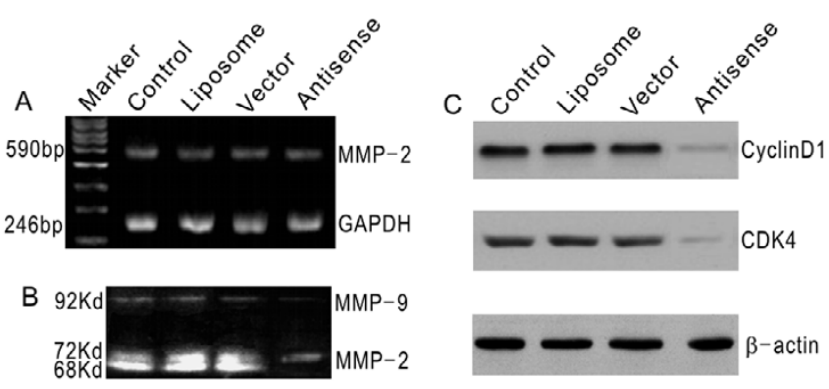

Figure 4

MMP2, cyclin DI and CDK4 expression level after antisense PCDGF construct transfection in SW626 cells. A, MMP2 mRNA expression level was unchanged after antisense PCDGF construct transfection in SW626 cells compared with control group detected by RT-PCR. B, MMP2 activation was inhibited after antisense PCDGF construct transfection in SW626 cells detected by zymography assay. The $92 \mathrm{KD}, 72 \mathrm{KD}$ and $68 \mathrm{KD}$ bands, which represented MMP2 activity, were very weak in antisense PCDGF construct transfection group compared with the control group. C, cyclin DI and CDK4 decreased after antisense PCDGF construct transfection in SW626 cells, which paralleled with the proliferation and invasion capability.

tive strategy for specific inhibition of PCDGF transcription and translation in ovarian cancer. Then a good cell model for observing the inhibitory effects of antisense PCDGF on their malignant phenotype of ovarian cancer cells was provided. MTT assay and Boyden chamber in vitro invasion assays were employed to examine the effect of PCDGF on proliferation and invasion the capability. Our results demonstrated that ovarian cancer cells transfected with antisense PCDGF grew more slowly and the invasion capability in vitro decreased sharply, compared with the vector transfected cells. In order to rule out the possibility of the non-specific effect, we adopted SiRNA strategy. The proliferation rates and invasion index were decreased in the SW626 cells and A2780 cells after PCDGF SiRNA transfection as expected.

Interestingly when we introduced antisense PCDGF into less invasive SKov3 cells, cell proliferation rate and invasion index decreased slightly without statistical significance (data not shown), which might indicate that antisense PCDGF worked more efficiently in highly invasive ovarian cancer cells.

Next we investigated the interrelated mechanism of these effects. Cyclin D1, one of the G1 cyclins, was identified independently from human and murine tumors as a putative proto-oncogene associated with chromosomal translocation, gene amplification, and proviral insertion. Constitutive overexpression of cyclin D1 is likely to con- tribute to the development of malignancy by reducing the dependency on mitogens and other extracellular signals that are normally required to promote progression through the late $\mathrm{G} 1$ restriction point $[24,25]$. In our pilot study the protein expression level of CyclinD1 and CDK4 in antisense PCDGF transfected cells were shown to be much lower than empty vector and other control groups. Our results implied that inhibition of PCDGF decreased cell proliferation and invasion through downregulation of cyclin D and CDK 4.

The changes in the expression and activity of MMP-2 involved in the degradation of the extracellular matrix were evaluated by a quantitative RT-PCR method and zymography assay. As we know, invasion across the basement membrane is among the earliest steps of epithelial tumor progression. Matrix metallo-proteinases, a family of zinc-dependent metallo-endopeptidases, are involved in the degradation of the extracellular matrix, a central element of tumor invasion and metastasis. One of these enzymes, MMP-2, is able to degrade type IV collagen, which is a major component of the basement membrane There was a significant relationship between activated MMP-2 and invasiveness, metastasis, and disease progression [26-29]. In zymography assays we found that the activated band of MMP-2 disappeared in antisense PCDGF transfected cells, suggesting that the antisense PCDGF vector could inhibit the activation of MMP-2 significantly. At the same time it was demonstrated that the antisense PCDGF did not change MMP-2 gene transcription.

In conclusion, our present study demonstrated that PCDGF expression level in ovarian cancer cells correlated well with their potential for proliferation and invasion. Inhibition of PCDGF by antisense PCDGF vector could decrease the proliferation and invasion capability markedly, partially reversing their malignant phenotype. Inhibition of PCDGF decreased cell proliferation and invasion through downregulation of cyclin D and CDK 4 and inactivation of MMP-2. Taken together, PCDGF might be a new target for antisense gene therapy of ovarian cancer.

\section{Conclusion}

Our present study demonstrated that PCDGF expression level in ovarian cancer cells correlated well with their capability of proliferation and invasion capability. Inhibition of PCDGF by antisense PCDGF transfection could downregulate the expression of cyclin D1, CDK4 and MMP-2, and markedly reverses malignant phenotype of ovarian cancer. PCDGF might be a new target for antisense gene therapy of ovarian cancer.

\section{Abbreviations}

PCDGF; PCcell-derivedgrowthfactor, TGF- $\beta$; transforminggrowthfactor- $\beta$, m-CSF; macrophagecolonystimulat- 
ingfactor, LPA; lysophosphatidicacid, PMSF; phenylmethylsulfonyl fluoride, SiRNA; small interference RNA

\section{Competing interests}

The author(s) declare that they have no competing interests.

\section{Authors' contributions}

YL and LX carried out these studies and manuscript preparation. GL, WW, XT, BW, GC, ZH, MW and SW participated in the experiments such as cell culture and preparation of nucleare extracts, flow cytometry analysis, immunofluorescence Staining and extracellular hydrogen peroxide production Assay etc. JZ, GX and YL took care laboratory supplies and maintained laboratory. DM directed the design and performance of the study. All authors read and approved the final manuscript.

\section{Acknowledgements}

This work was supported by grants from the National Science Foundation of China (No. 30025017, 30571950) and the "973" Program of China (No. 2002CB5 I3100).

\section{References}

I. Zhou J, Gao G, Crabb JW, Serrero G: Purification of an autocrine growth factor homologous with mouse epithelin precursor from a highly tumorigeniec cell line. J Biol Chem 1993, 268: 10863-10869.

2. Zhang H, Serrero G: Inhibition of tumorigenicity of the teratoma PC cell line by transfection with antisense cDNA for PC cell-derived growth factor (PCDGF, epithelin/granulin precursor). Cell Biology 1998, 95: I4202-14207.

3. He Z, Bateman A: Progranulin gene expression regulates epithelial cell growth and promotes tumor growth in vivo. Cancer Research 1999, 59:3222-3229.

4. Daniel R, He Z, Carmichael KP, Halper J, Bateman A: Cellular localization of gene expression for progranulin. J Histochem Cytochem 2000, 48:999-1009.

5. Lu R, Serrero G: Inhibition of PC cell-derived growth factor (PCDGF, epithelin/granulin precursor) expression by antisense PCDGF cDNA transfection inhibits tumorigenicity of the human breast carcinoma cell line MDA-MB-468. Proc Natl Acad Sci 2000, 97:3993-3998.

6. Lu R, Serrero G: Mediation of estrogen mitogenic effect in human breast cancer MCF-7 cells by PC-cell-derived growth factor (PCDGF/granulin precursor). Proc Natl Acad Sci 200I, 98: $142-147$.

7. Tangkeangsirisin W, Hayashi J, Serrero G: PC cell-derived growth factor mediates tamoxifen resistance and promotes tumor growth of human breast cancer cells. Cancer Res 2004, 64:1737-1743.

8. Xu SQ, Dazhi Tang, Scott Chamberlain, Pronk G, Masiarz FR, Kaur S, Prisco M, Zanocco-Marani T, Baserga R: The granulin/epithelin precursor abrogates the requirements for the insulin-like growth factor I receptor for growth in vitro. J Biol Chem 1998, 273:20078-20083

9. He Z, Ismail A, Kriazhev L, Sadvakassova G, Bateman A: Progranulin (PC-cell-derived growth factor/acrogranin) regulates invasion and cell survival. Cancer Research 2002, 62:5590-5596.

10. Wang W, Hayashi J, Kim WE, Serrero G: PC cell-derived growth factor (granulin precursor) expression and action in human multiple myeloma. Clin Cancer Res 2003, 9:222I-2228.

II. Fang X, Gaudette D, Furui T, Mao M, Estrella V, Eder A, Pustilnik T, Sasagawa T, Lapushin R, Yu S, Jaffe RB, Wiener JR, Erickson JR, Mills GB: Lysophospholipid growth factorsin the initiation, progression, metastases, and management of ovarian cancer. Ann N Y Acad Sci 2000, 905:188-208.
12. Berchuck A, Rodriguez G, Olt G, Whitaker R, Boente MP, Arrick BA Clarke-Pearson DL, Bast RC: Regulation of growth of normal ovarian epithelial cells and ovarian cancer cell lines by transforming growth factor- $\beta$. Am J Obstet Gynecol 1992, 166:676-684

13. Hurteau JA, Allison B, Sutton GP, Moore DH, Look KY, Hurd W, Bigsby RM: Transforming growth factor- $\beta_{-}$differentially inhibits epithelial ovarian carcinoma cells from primary and metastatic isolates without up-regulation of p2IWAFI. Cancer (Phila.) 1999, 85:1810-1815.

14. Kawakami Y, Nagai N, Ohama K, Zeki K, Kuroda E, Yamashita U: Macrophage-colony stimulating factor inhibits the growth of human ovarian cancer cells in vitro. Eur J Cancer 2000, 36: $1991-1997$.

15. Jones MB, Michener CM, Blanchette JO, Kuznetsov VA, Raffeld M, Serrero G, Emmert-Buck MR, Petricoin EF, Krizman DB, Liotta LA, Kohn EC: The granulin-epithelin precursor/PC-cell- derived growth factor is a growth factor for epithelial ovarian cancer. Clin Cancer Res 2003, 9:44-5I.

16. Blons H, Laccourreye O, Laurent-Puig P: Cellular and neoplastic otorhinolaryngologic changes, molecular markers and therapeutic potential. Ann Otolaryngol Chir Cervicofac. Review French 2003, 120:152-160.

17. Shao JC, Wu JF, Wang DB, Qin R, Zhang H: Relationship between the expression of human telomerase reverse transcriptase gene and cell cycle regulators in gastric cancer and its significance. World J Gastroenterol 2003, 9:427-43I.

18. Umekita $Y$, Ohi $Y$, Sagara $Y$, Yoshida H: Overexpression of cyclinDI predicts for poor prognosis in estrogen receptornegative breast cancer patients. Int J Cancer 2002, 98:4I5-4I8.

19. Niedbala MJ, Crickard K, Bernacki RJ: In vitro degradation of extracellular matrix by human ovarian carcinoma cells. Clin Exp Metast 1987, 5:181-197.

20. Afzal S, Lalani EN, Foulkes WD, Boyce B, Tickle S, Cardillo MR, Baker T, Pignatelli M, Stamp GWH: Matrix metalloproteinase-2 and tissue inhibitor of metalloproteinase- 2 expression and synthetic matrix metalloproteinase-2 inhibitor binding in ovarian carcinomas and tumor cell lines. Lab Invest 1996, 2:406-42 I.

2I. Leroy-Dudal J, Demeilliers C, Gallet O, Pauthe E, Dutoit S, Agniel R, Gauduchon P, Carreiras F: Transmigration of human ovarian adenocarcinoma cells through endothelial extracellular matrix involves alphav integrins and the participation of MMP2. Int J Cancer 2005, I | 4:53 I-543.

22. Miyamoto S, Mekada E: Biological behavior of ovarian cancer. Nippon Rinsho 2004:458-462.

23. Kamrava M, Simpkins F, Alejandro E, Michener C, Meltzer E, Kohn EC: Lysophosphatidic acid and endothelin-induced proliferation of ovarian cancer cell lines is mitigated by neutralization of granulin-epithelin precursor (GEP), a prosurvival factor for ovarian cancer. Oncogene 2005, 24:7084-7093.

24. Dimova I, Zaharieva B, Raicheva S, Milev I, Dimitrov R, Doganov N, Aleksandrov M, Todorov T, Toncheva D: Association of CyclinD I copy number changes with histological type in ovarian tumors. Acta Oncol 2004, 43:675-679.

25. Hashiguchi $Y$, Tsuda H, Inoue T, Nishimura S, Suzuki T, Kawamura N: Alteration of cell cycle regulators correlates with survival in epithelial ovarian cancer patients. Hum Pathol 2004, 35:165-175

26. Belotti D, Paganoni P, Manenti L, Garofalo A, Marchini S, Taraboletti G, Giavazzi R: Matrix metalloproteinases (MMP9 and MMP2) induce the release of vascular endothelial growth factor (VEGF) by ovarian carcinoma cells: implications for ascites formation. Cancer Res 2003, 63:5224-5229.

27. Okamoto T, Niu R, Yamada S: Increased expression of tissue inhibitor of metalloproteinase-2 in clear cell carcinoma of the ovary. Mol Hum Reprod 2003, 9:569-575.

28. Manenti L, Paganoni P, Floriani I, Landoni F, Torri V, Buda A, Taraboletti G, Labianca R, Belotti D, Giavazzi R: Expression levels of vascular endothelial growth factor, matrix metalloproteinases 2 and 9 and tissue inhibitor of metalloproteinases $I$ and 2 in the plasma of patients with ovarian carcinoma. Eur / Cancer 2003, 39: 1948-1956.

29. Holle L, Song W, Holle E, Wei Y, Wagner T, Yu X: A matrix metalloproteinase 2 cleavable melittin/avidin conjugate specifically targets tumor cells in vitro and in vivo. Int J Oncol 2003, 22:93-98. 


\section{Pre-publication history}

The pre-publication history for this paper can be accessed here:

http://www.biomedcentral.com/1471-2407/7/22/prepub

Publish with Biomed Central and every scientist can read your work free of charge

"BioMed Central will be the most significant development for disseminating the results of biomedical research in our lifetime. " Sir Paul Nurse, Cancer Research UK

Your research papers will be:

- available free of charge to the entire biomedical community

- peer reviewed and published immediately upon acceptance

- cited in PubMed and archived on PubMed Central

- yours - you keep the copyright 